\title{
First- Third generation EGFR inhibitor combined with cytotoxic chemotherapy in elderly Patients with advanced lung adenocarcinom in routine clinical practice-results from A Subgroup Analysis
}

Ming-Wei Chen , ( $\sim$ zfyhat@126.com )

Xi'an Jiaotong University https://orcid.org/0000-0003-4016-8855

An-Tai He .

GHINA raditional protection research institute hospital

Yi Pei .

Shanxi Bethune Hospital

\section{Research Article}

Keywords: lung adenocarcinoma, EGFR inhibitor, Cytotoxic chemotherapy, Osimertinib

Posted Date: June 1st, 2021

DOI: https://doi.org/10.21203/rs.3.rs-545928/v1

License: (c) (1) This work is licensed under a Creative Commons Attribution 4.0 International License.

Read Full License 


\section{Abstract}

\section{Background}

The third generation Epidermal Growth Factor Receptor (EGFR) Tyrosine Kinase Inhibitor (TKI) osimertinib has been initially approved for T790M positive lung adenocarcinoma patients and more recently for firstline treatment of EGFR-mutant T790M negative lung adenocarcinoma, Similarly to previous generation TKIs, despite the high response rate, disease progression eventually occurs and current clinical research is focused on novel strategies to delay the emergence of osimertinib resistance.In this study,we investigated a the combination of osimertinib/ gefitinib/ erlotinib with cytotoxic chemotherapy for EGFR-mutated positive lung adenocarcinoma patients in long-term survival outcomes.

\section{Method}

We enrolled $\bigotimes \mathrm{b}-\mathrm{IV}$ stage lung adenocarcinoma patients with an EGFR mutation $\otimes$ Patients receiving standard Osimertinib,Gefitinib,Erlotinip alone treatment and Osimertinib,Gefitinib and Erlotinip with cytotoxic chemotherapy treatment were retrospectively reviewed.The performance status were collected, The response rate, progression-free survival (PFS) and overall survival (OS) and toxicity profile were analyzed.

\section{Result}

Between January 2014 to Dec 2020,240 patients with $₫$ b-『stages lung adenocarcinoma were enrolled from a institution.All patients who received different standard treatment respectively,were divided into four groups, 64 who received $₫$ gefitinib or Erlotinb)with cytotoxic chemotherapy, 60 who received single gefitinib or erlotinib.58 who received (Osimertinib) with cytotoxic chemotherapy, 58 who received single (Osimertinib) were eligible for this study.First generation Chemical-TKltherapy group PFS vs First generation TKI therapy alone PFS.P<0.05. Mean Survival Time 22.00 month,95\% CI[16.29,27.70] VS 16.00 month.95\% CI[11.98,20.01].First generation Chemical-TKItherapy group OS vs First generation TKI therapy alone OS. $\mathrm{P}<0.05$. Mean Survival Time 32.00 month,95\%Cl[25.29,3871] VS 28.00 month, 95\% CI[14.58,41.41].Third generation Chemical-TKItherapy group PFS vs Third generation TKI therapy PFS. P<0.001.Mean Survival Time 40.00,95\%CI[28.12,51.87] VS 26.66 95\%CI[24.77,29.22].Third generation Chemical-TKItherapy group OS vs Third generation TKI therapy OS.P<0.05. Mean Survival Time 48.00.95\% CI[42.81,53.18] VS 36.00. 95\% CI[34.71,38.28].First-Third generation Chemical-TKItherapy group PFS vs.First-Third generation TKI therapy alone PFS.P<0.001. Mean Survival Time $28.00,95 \% \mathrm{CI}[24.86,31.11]$ VS $17.0095 \% \mathrm{CI}[13.83,20.16]$.First-Third generation Chemical-TKItherapy group OS vs First-Third generation TKI therapy alone OS.P<0.001. Mean Survival Time $41.00 .95 \% \mathrm{CI}[31.70,50.30]$ VS 29.00. 95\% CI[17.68,38.31].Cox regression models showed a significant prognostic factors for OS were old age (55-69 years) ( $\mathrm{HR}=0.49[0.28-0.89], p<0.02)$ and gene mutation (Positive) ( $\mathrm{HR}=0.15$ [0.07$0.29], p<0.05)$,First add third generationTKI with chemicaltherapy $(\mathrm{HR}=0.56[0.35-0.89], p<0.02)$.

\section{Conclusion}


First-Third generation EGFR inhibitor combined with cytotoxic chemotherapy represents a suitable palliative treatment option in further therapy lines for elderly patients with advanced lung adenocarcinoma. The results obtained under real-life conditions add to our understanding of the benefits and risks of First-Third generation EGFR inhibitor combined with cytotoxic chemotherapy in routine clinical practice.

\section{Background}

Lung cancer is the leading cause of cancer deaths worldwide [1], about $85 \%$ of cases are diagnosed as non-small-cell lung cancer (NSCLC). The median age of NSCLC patients is 70 years and the disease is usually diagnosed in advanced stages,when curative surgery is no longer feasible. In metastasized disease, first-line chemotherapy is often not successful and the 5-year survival rate is only $4.2 \%$ [3]. NSCLC is histologically classified into the major subtypes adenocarcinoma ( 40\%) [2, 3],Recurring mutations have been reported in genes coding for epidermal growth factor receptors (EGFR) in 10-40\% of adenocarcinomas [4,5], EGFR mutations can lead to constitutive activation of anti-apoptotic and proliferation signaling pathways, which promote cancer progression [6],EGFR tyrosine kinase inhibitors (TKI) are the preferred first-line treatment for advanced NSCLC with EGFR mutations [7, 8], Treating NSCLC is challenging because of the advanced age of patients.As EGFR-TKI avoid the systemic side effects of traditional chemotherapy,they might be more suitable for treating elderly patients [9]. Osimertinib, a third-generation EGFR-TKI that selectively binds the $\mathrm{C797}$ residue inhibiting the T790M mutation, has shown high activity in term of Progression-Free Survival (PFS) and overall response rate in EGFR-T790M positive patients $[10,11]$ and efficacy superior to gefitinib/erlotinib in the first-line treatment by approximately a 9 months advantage in PFS [12]. However,acquired resistance occurs also to osimertinib either in T790M-positive NSCLC patients or in patients treated in first-line $[13,14]$.EGFRdependent or independent mechanisms of resistance have been described even if they remain not completely understood [15]. EGFR G796/C797, L792 and L718/G719 mutations, MET and HER2 amplification, BRAF, KRAS, and PIK3CA mutations, oncogenic fusion mutations in FGFR3, RET, and NTRK were recently identified in a large cohorts of osimertinib-resistant lung cancer patients either treated in second-line [16] and in first-line.Knowledge of these mechanisms is relevant in order to develop new therapeutic strategies to overcome TKI-resistance; however, how prevent or delay the acquisition of resistance remains an important issue.Some data indicated that in PC9 cell line and xenograft models, the combination of gefitinib with pemetrexed or the intermittent combination of pemetrexed and gefitinib prevented some the appearance of gefitinib resistance mediated by T790M mutation and epithelialmesenchymal transition [17]; however,the combination was ineffective when gefitinib was administered before pemetrexed.Theoretically,Chemotherapy,given its different and more generic mechanism of action,can postpone the resistance to EGFR-TKIs by limiting the tumor heterogeneity,thus improving the efficacy of treatment either in first-and second-line.Osimertinib combined or intercalated with chemotherapy deserves to be considered either for patients in progression after first/second-generation TKIs or in first-line setting.Our study was undertaken to explore a long-term survival outcomes in the 
combination of osimertinib with pemetrexed add platinum and the combination of gefitinib/erlotinib with pemetrexed add platinum in elderly lung adenocarcinoma patients.

\section{Method}

The flowchart of our study is shown in Fig. 1.

\section{Patient}

Method

Between January 2014 and Dec 2020, 240 patients were diagnosed in Shan-Xi Bethune Hospital,Taiyuan City,China.

All patients were aged between 55 and 84 years old. Inclusion criteria were as follows:(1) Pathological diagnosis of lung adenocarcinoma; (2) Karnofsky performance score $>60$; (3) Adequate organ (white blood cell > 4.0×10/L; neutrophil > 2.0×10/L; hemoglobin > $90 \mathrm{~g} / \mathrm{L}$; platelet $>100 \times 10^{9} / \mathrm{L}$; aspartate aminotransferase/alanine transaminase $<2.5$ upper limit of normal;(4) Routine evaluations were performed on patients, including physical examination,electrocardiography,chest and abdominal

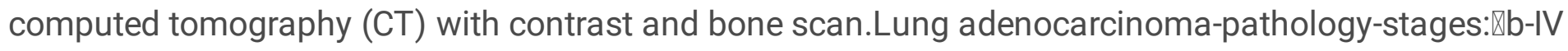
stages (Table 1).

\section{Treatment method}

Table 2.Chemotherapy:(1) pemetrexed plus carboplatin or cisplatin. (2) Docetaxel plus carboplatin or cisplatin. and so on.Chemotherapy used for 4 to 6 weeks or more.TKI therapy: Before TKI therapy, Tumor gene mutation profile, including EGFRT790M,ALK-M,

KRAS-M,METM „RETM,ROS, and so on gene, was performed.If the test was positive,first-generationTKI therapy drugs,Gefitinib, Erlotinib,Ectinib were used.After the first-generation drugs showed resistance,Third-generation TKI therapy drug Osimertinib was used.Eligible patients were randomized to one of the following treatment arms:240 patients divided into 2 group.First group 124patients. 60 patients alone Gefitinib group $250 \mathrm{mg}$ / each 1/ d, or Erlotinip group $150 \mathrm{mg}$, each 1/ d, oral administration.Oral administration until disease progression.64 patients,Gefitinib/ Erlotinip with chemotherapy group,Chemotherapy regimen:intravenously administered pemetrexed sodium on day 1 of each cycle,500 $\mathrm{mg} / \mathrm{m} 2$, dose.Cisplatin was given intravenously on days 2,3 and 4, $30 \mathrm{mg} / \mathrm{m} 2$,dose or carboplatin on day 1,The doses were $10 \mathrm{mg} / \mathrm{m} 2$,One cycle continuous treatment for $4 \sim 6$ cycles or more.pemetrexed $175 \mathrm{mg} / \mathrm{m} 2$, and carboplatin $10 \mathrm{mg} / \mathrm{m} 2$, administered intravenously on day.intercalated with Gefitinib $250 \mathrm{mg}$ group or Erlotinip group $150 \mathrm{mg}$ orally on days until progressive disease,or until a discontinuation criterion was met.Second group116 patients,58 patients alone osimertinib group $80 \mathrm{mg} / \mathrm{d}, 0 \mathrm{ral}$ administration until disease progression. 58 patients Osimertinib targeted therapy with chemotherapy,Chemotherapy regimen was same as first Group,intercalated with osimertinib group 80 $\mathrm{mg} / \mathrm{d}$,Oral administration until disease progression. 


\section{Evaluation}

Tumor response was assessed as complete response (CR), partial response (PR), stable disease (SD), or progression disease (PD) in accordance with the standard of RECIST [18]. A CR was defined as the complete disappearance of all clinically detectable tumors for at least 4 weeks. A PR was defined as an at least $30 \%$ decrease in the sum of the longest diameters of the target lesions for more than 4 weeks without new area of malignant disease. PD indicated an at least $20 \%$ increase in the sum of the longest diameter of the target lesions or a new malignant lesion.Stable disease was defined as insufficient shrinkage to qualify for PR and insufficient increase to qualify for PD.An objective response rate (ORR) indicated the proportion of patients achieved $C R$ and $P R$, while a disease control rate (DCR) indicated the proportion of patients achieved CR, PR and SD.Progression-free survival (PFS) was measured from Day 1 of treatment until the first objective or clinical sign of disease progression.Overall survival (OS) was measured from Day 1 of treatment until the date of death.Adverse effects including 5 degrees (0-IV) were evaluated following the standard enacted by the World Health Organization in 1981. The follow-up was performed through telephone by the trained investigators with good communication skills and knowledge on the diagnosis.After diagnosed with lung adenocarcinoma,the survival time was determined.After discharge, the patients were inspected every three months in the first one year and there after until death. A series of evaluations were conducted including physical examination, chest radiography,CT/magnetic resonance with the contrast of the metastatic sites,abdominal sonography, PET-CT was considered when necessary.

\section{Statistical analyses}

The incidence of time-to-event data in different subgroups was analyzed using the Kaplan-Meier method and compared with the log-rank test. The potential factors,survival and response data were analyzed overall and in the following subgroups:age (55-69 or $\geq 70$ years),EGFR mutation (positive or negative) and gender,metastatic lesions1-2 or $\geq 3$. Treatment method $\nabla$ TKI-chemicaltherapy,or TKI therapy alone add chemical therapy alone).the OS was additionally investigated using Cox regression models (considering single and multiple factors).Multivariable Cox regression analyses were used to estimate the HR and $95 \%$ $\mathrm{Cl}$ for the relationship between the characteristics and overall survival.Statistical analyses were performed using SPSS (Mac ver. 21.0, IBM Corp.).All statistical tests in our study are 2-tailed.A $p$-value of less than 0.05 is considered statistically significant.

\section{Results}

\section{Table 1 Patient baseline characteristics $(N=240)$}




\begin{tabular}{|c|c|}
\hline Characteristic & No. (\%) \\
\hline \multicolumn{2}{|l|}{ Age (yr) } \\
\hline $55-69$ & $152(63.15)$ \\
\hline$\geq 70$ & $88(36.84)$ \\
\hline \multicolumn{2}{|l|}{ Gender } \\
\hline Male & $107(44.73)$ \\
\hline Female & $133(55.26)$ \\
\hline \multicolumn{2}{|l|}{ Gene mutation $\nabla$ Tested $\nabla$} \\
\hline EGFR + & $100(41.44)$ \\
\hline EGFR - & $57(23.68)$ \\
\hline Wild-type & $5(1.97)$ \\
\hline T790M mutations + & $44(18.42)$ \\
\hline ALK mutations+ & $6(2.63)$ \\
\hline KRAS mutations+ & $13(5.26)$ \\
\hline RET mutations+ & $8(3.28)$ \\
\hline MET mutations+ & $8(3.28)$ \\
\hline \multicolumn{2}{|l|}{ EGFR gene mutation site-n } \\
\hline Exon18 & $11(4.76)$ \\
\hline Exon19 & $57(23.80)$ \\
\hline Exon19 + Exon21 & $4(1.58)$ \\
\hline Exon $20+$ & $8(3.17)$ \\
\hline Exon21L858 & 61(25.39) \\
\hline \multicolumn{2}{|l|}{ Chemical-TKI therapy } \\
\hline Yes & $122(50.83)$ \\
\hline No & $118(49.16)$ \\
\hline First-generation Chemical-TKI therapy & $64(26.66)$ \\
\hline First-third generation Chemical-TKI therapy & $58(24.16)$ \\
\hline \multicolumn{2}{|l|}{ TKI therapy alone } \\
\hline Yes & 118(49.58) \\
\hline
\end{tabular}




\begin{tabular}{|ll|}
\hline Characteristic & No. (\%) \\
\hline No & $122(50.83)$ \\
\hline First generation TKI therapy alone & $60(25.00)$ \\
\hline First-third generation TKI therapy alone & $58(24.16)$ \\
\hline
\end{tabular}

Table 2.Drugs administered as First generationTKI therapy alone,First generation Chemical-TKI therapy, First-third generation TKI therapy alone,First-third generation Chemical-TKItherapy. 


\begin{tabular}{|c|c|c|}
\hline & $\mathrm{N}$ & $\%$ \\
\hline & 240 & $100 \%$ \\
\hline First generationTKI therapy alone & 46 & $19 \%$ \\
\hline \multicolumn{3}{|l|}{ Type of treatment } \\
\hline Gefitinib & 22 & $9.2 \%$ \\
\hline Erlotinib & 24 & $9.8 \%$ \\
\hline First generation Chemical-TKI therapy & 131 & $54.38 \%$ \\
\hline \multicolumn{3}{|l|}{ Type of treatment } \\
\hline Erlotinib+Docetaxel+Carboplatin & 37 & $15.35 \%$ \\
\hline Gefitinib+Pemetrexed+Carboplatin & 40 & $16.66 \%$ \\
\hline Gefitinib+Vinorelbine+Carboplatin & 19 & $7.89 \%$ \\
\hline Erlotinib+Paclitaxel+Carboplatin & 19 & $7.89 \%$ \\
\hline Gefitinib+Etoposide VP16+Cisplatin & 13 & $5.26 \%$ \\
\hline Gefitinib+Bevacizumab+ Cisplatin+Pemetrexed & 10 & $3.94 \%$ \\
\hline First-third generation TKI therapy alone & 52 & $21.49 \%$ \\
\hline \multicolumn{3}{|l|}{ Type of treatment } \\
\hline Osimertinib+Gefitinib & 25 & $10.52 \%$ \\
\hline Osimertinib & 26 & $10.96 \%$ \\
\hline First-third generation Chemical-TKItherapy & 58 & $24.12 \%$ \\
\hline \multicolumn{3}{|l|}{ Type of treatment } \\
\hline Osimertinib+Gefitinib+Docetaxel+Carboplatin & 21 & $8.77 \%$ \\
\hline Osimertinib+Erlotinib+Pemetrexed+Cisplatin & 16 & $6.57 \%$ \\
\hline Osimertinib+Pemetrexed+Cisplatin & 11 & $4.38 \%$ \\
\hline Osimertinib+Docetaxel+Carboplatin & 11 & $4.38 \%$ \\
\hline
\end{tabular}

\section{Six or more cycles of chemotherapy were completed in $95 \%$ of patients and only one cycle was completed in $4.5 \%$ of patients.}

\section{Table 3. Results of Cox univariate and multivariate regression analysis}




\begin{tabular}{|c|c|c|c|c|}
\hline Characteristic & $\begin{array}{l}\text { Univariable } \\
\text { analyses }\end{array}$ & $\begin{array}{l}\text { Multivariable } \\
\text { analyses }\end{array}$ & & \\
\hline $\begin{array}{l}\text { Hazard ratio } \\
(95 \% \mathrm{Cl})\end{array}$ & $p$-value & $\begin{array}{l}\text { Hazard ratio } \\
(95 \% \mathrm{Cl})\end{array}$ & $p$-value & \\
\hline \multicolumn{5}{|l|}{ Age (yr) } \\
\hline $55-69$ & Reference & & Reference & \\
\hline$\geq 70$ & $\begin{array}{l}0.49(0.30- \\
0.81)\end{array}$ & 0.005 & $\begin{array}{l}0.49(0.28- \\
0.89)\end{array}$ & 0.02 \\
\hline \multicolumn{5}{|l|}{ Gender } \\
\hline Male & Reference & & Reference & \\
\hline Female & $\begin{array}{l}0.77(0.53- \\
0.96)\end{array}$ & 0.04 & $\begin{array}{l}0.92(0.56- \\
1.53)\end{array}$ & 0.76 \\
\hline \multicolumn{5}{|l|}{ gene mutation } \\
\hline No & Reference & & Reference & \\
\hline Yes & $\begin{array}{l}0.72(0.07- \\
0.25)\end{array}$ & 0.01 & $\begin{array}{l}0.15(0.07- \\
0.29)\end{array}$ & 0.01 \\
\hline
\end{tabular}

First add third generation TKItherapy with Chemicaltherapy

\begin{tabular}{lllll} 
No & Reference & \multicolumn{2}{c}{ Reference } \\
Yes & $0.56(0.35-$ & 0.02 & $1.50(0.42-$ & 0.52 \\
& $0.93)$ & & $5.31)$ & \\
\hline
\end{tabular}

First add third generation

TKltherapy alone

\begin{tabular}{lllll} 
No & Reference & \multicolumn{2}{l}{ Reference } \\
Yes & $1.11(0.64-$ & 0.72 & $0.71(0.18-$ & 0.62 \\
& $1.91)$ & & $2.71)$ & \\
\hline
\end{tabular}

Cl.Confidence interval.Cox regression models with adjustment for single factors showed a significant influence of age $(\mathrm{yr})(p=0.005)$, gender $(p=0.04)$ and EGFR status $(p=0.01)$, first add third generationTKIherapy with chemicaltherapy $(p=0.02)$ on OS. Accordingly, Age (yr) $55-69$ had an $51 \%$ reduced risk of death compared to $\geq 70$ (yr) (hazard ratio( [HR] 0.49, 95\% Cl 0.30-0.81).Females had an almost $30 \%$ reduced risk of death compared to males (hazard ratio( [HR] 0.71, 95\% $\mathrm{Cl} 0.53-0.96$ ). Patients with an EGFR mutation had an almost $28 \%$ reduced risk of death compared to negative 
patients([HR] 0.72,95\% Cl 0.07-0.25).First add third generationTKItherapy with chemicaltherapy had an almost $54 \%$ reduced risk of death compared to first add third generation TKItherapy alone.

\section{Table 4}

Clinical endpoints and Treatment outcomes:TKItherapy with Chemical-TKLtherapy and TKLtherapy alone stratified by patient baseline characteristics, for the overall patients with Lung adenocarcinoma.

\begin{tabular}{|c|c|c|c|c|c|c|}
\hline & $\begin{array}{l}\text { First } \\
\text { generation }\end{array}$ & $\begin{array}{l}\text { First } \\
\text { generation }\end{array}$ & $\begin{array}{l}\mathrm{p}- \\
\text { value }\end{array}$ & $\begin{array}{l}\text { Third } \\
\text { generation }\end{array}$ & $\begin{array}{l}\text { Third } \\
\text { generation }\end{array}$ & $\begin{array}{l}\mathrm{p}- \\
\text { value }\end{array}$ \\
\hline & $\begin{array}{l}\text { Chemical- } \\
\text { TKItherapy }\end{array}$ & $\begin{array}{l}\text { TKItherapy } \\
\text { alone }\end{array}$ & & $\begin{array}{l}\text { Chemical- } \\
\text { TKItherapy }\end{array}$ & $\begin{array}{l}\text { TKItherapy } \\
\text { alone }\end{array}$ & \\
\hline & $(N=64)(\%)$ & $(N=60)(\%)$ & & $(N=58)(\%)$ & $(N=58)(\%)$ & \\
\hline Response, n (\%) & & & & & & \\
\hline $\begin{array}{l}\text { Partial } \\
\text { response (PR) }\end{array}$ & $45(70.23)$ & $33(55.23)$ & & $47(80.23)$ & $43(73.45)$ & \\
\hline $\begin{array}{l}\text { Stable disease } \\
\mathbb{\triangle S D Q}\end{array}$ & $21(32.72)$ & $12(20.12)$ & & $28(48.64)$ & $24(41.17)$ & \\
\hline$\geq 6$ weeks & & & & & & \\
\hline $\begin{array}{l}\text { Progressive } \\
\text { disease (PD) }\end{array}$ & $3(5.41)$ & 6冈10.34】 & & $2(3.11)$ & $3(5.12)$ & \\
\hline ORR (CR+PR) & 49囚77.12】 & $29 \llbracket 47.45 \rrbracket$ & $<0.05$ & 52(89.34】 & $44(75.43)$ & $<0.05$ \\
\hline $\begin{array}{l}\mathrm{DCR} \\
(\mathrm{CR}+\mathrm{PR}+\mathrm{SD})\end{array}$ & $54 \rrbracket 84.34 \rrbracket$ & $41 \rrbracket 67.54 \rrbracket$ & $<0.05$ & 55(95.34) & $46(79.21)$ & $<0.05$ \\
\hline Survival time & & & & & & \\
\hline $\begin{array}{l}\text { PFS, months, } \\
\text { median }(95 \% \mathrm{Cl})\end{array}$ & $\begin{array}{l}22.00(16.29- \\
27.70)\end{array}$ & $\begin{array}{l}\text { 16.36(11.98- } \\
20.01)\end{array}$ & $<0.001$ & $\begin{array}{l}40.00(28.12- \\
51.87)\end{array}$ & $\begin{array}{l}27.00(24.78- \\
29.22)\end{array}$ & $<0.05$ \\
\hline $\begin{array}{l}\text { OS, months, } \\
\text { median ( } 95 \% \mathrm{Cl})\end{array}$ & $\begin{array}{l}32.00(25.29- \\
38.71)\end{array}$ & $\begin{array}{l}28.00(14.58- \\
41.42)\end{array}$ & $<0.02$ & $\begin{array}{l}48.00(42.81- \\
53.18)\end{array}$ & $\begin{array}{l}36.00(34.72- \\
50.27)\end{array}$ & $<0.02$ \\
\hline
\end{tabular}

ORR, overall response rate; $\mathrm{CR}$, complete response; $\mathrm{DCR}$, disease control rate; $\mathrm{Cl}$, confidence interval;PFS, progression-free survival for treatment; OS, overall survival for treatment.

\section{Table 5}

Summary of the most common adverse events for the overall patients with Lung adenocarcinoma. 


\begin{tabular}{|c|c|c|c|c|}
\hline $\begin{array}{l}\text { Adverse event with } \\
\text { AE (Grade 1-4) }\end{array}$ & $\begin{array}{l}\text { First generation } \\
\text { Chemical-TKltherapy } \\
(N=64)(\%) \text { All grade }\end{array}$ & $\begin{array}{l}\text { First } \\
\text { generation } \\
\text { TKItherapy } \\
\text { alone }(N= \\
60)(\%) \text { All } \\
\text { grade }\end{array}$ & $\begin{array}{l}\text { Third generation } \\
\text { Chemical-TKltherapy } \\
(N=58)(\%) \text { All grade }\end{array}$ & $\begin{array}{l}\text { Third } \\
\text { generation } \\
\text { TKItherapy } \\
\text { alone }(N= \\
58)(\%) \text { All } \\
\text { grade }\end{array}$ \\
\hline Skin rash & $40(63.12)$ & $37(61.48)$ & $34(58.32)$ & $31(53.02)$ \\
\hline Anorexia & $34(53.12)$ & $25(42.21)$ & $25(42.43)$ & $18(31.81)$ \\
\hline Cough & $30(46.12)$ & $25(40.23)$ & $21(36.23)$ & 19(33.31) \\
\hline Nausea & 28(43.12) & $18(30.23)$ & 18(30.12) & $14(24.21)$ \\
\hline Fatigue & 19 (29.09) & $17(27.58)$ & $9(15.13)$ & $6(10.61)$ \\
\hline Diarrhea & $30(47.12)$ & $26(43.34)$ & $24(41.12)$ & 18(31.81) \\
\hline Neutropenia & $21(32.12)$ & $16(27.12)$ & $15(26.12)$ & 11(18.22) \\
\hline Anemia & $28(43.00)$ & 21(35.12) & 19 (32.12) & 16(27.31) \\
\hline Thrombocytopenia & $26(40.07)$ & 19(32.12) & 19 (32.12) & $16(27.31)$ \\
\hline Increased LFT & $35(54.54)$ & 25(41.72) & 11(18.13) & $8(13.61)$ \\
\hline Mucositis & 12 (18.18) & $12(20.68)$ & $9(15.23)$ & $0(0.00)$ \\
\hline
\end{tabular}

$A E$ adverse event; Grgrade; $N$ number, $L F T$ liver function test

During the study,794 AEs were observed in 240 patients (Table 5).According to the common toxicity criteria for adverse events (CTC), The most commonly reported AEs were rash and anorexia囚diarrhea followed by increased LFT, cough,nausea, anemia and neutropenia. Most of the toxicity was grade 1 to 2 , and remitted after treatment. The frequency of AEs was not significantly affected by age or EGFR mutation status (data not shown).All AEs reported were consistent with those described in the summary of product characteristics [18].

\section{Discussion}

The study was designed to evaluate the effect of intercalation therapy with gefitinib or erlotinib or osimertinib with platinumar add pemetrexed chemotherapy.Our first generation target group includes gefitinib,erlotinib.The study demonstin relation to PFS, and OS.Toxicity profiles were generally clinically tolerabled. In another studies are same[19-24],the sequence-dependent synergism between platinumar add pemetrexed and gefitinib was demonstrated in human lung cancer cell lines with both wild-type and mutant EGFR genes [25].In this trial, the patients who received a combination of gefitinib with carboplatinpemetrexed showed a statistically significant benefit in survival (PFS of 20.90 vs 11.20 months, $p<0.001$ and $O S$ of 52.20 vs $38.80, p<0.013$ for gefitinib and carboplatin/pemetrexed and for gefitinib alone, 
respectively).Several later phase $\mathrm{I} / \mathrm{Il}$ clinical studies showed that an intercalated regimen of chemotherapy and EGFR TKI were safe and effective [26-28, 29].WSW clinical studies reported that the intercalated regimen offered superior efficacy compared to chemotherapy or EGFR TKIs alone [30, 31]. In a three-arm phase II study, The combination was suggested as a new treatment option for patients with unknown EGFR status in a previous clinical study [30],Although molecular tests are used routinely in clinical practice, EGFR status remains unknown in certain patients. We think that the intercalated strategy could be effective in patients with wild-type or unknown EGFR status.According to several clinical studies, Intercalated treatment might be a promising approach for patients with lung adenocarcinoma with EGFR mutant disease or selected patient with unknown EGFR mutation status, [31-32].Our results are first generation Chemical-TKItherapy group PFS vs first generation TKI therapy alone PFS. $P<0.05$. Mean Survival Time PFS 22.00,95\%CI[17.55,22.50] VS 16.00 95\%CI[13.59,19.13], First generation ChemicalTKItherapy group OS vs First generation TKI therapy alone OS. $P<0.01$. Mean Survival Time OS $32.00,95 \% \mathrm{Cl}[32.08,42.23]$ VS $28.0095 \% \mathrm{Cl}[19.09,34.24]$. First generation Chemical-TKItherapy group vs First generation TKI therapy alone had a stronger effect on ORR and DCR.Osimertinib is a third-generation EGFR TKI,A large rando mized trial comparing osimertinib to gefitinib or erlotinib reported that PFS was significantly longer in the osimertinib arms, and time to CNS metastases was significantly delayed because osimertinib crosses the blood-brain barrier.Toxicity rates were lower with osimertinib than the first-generation inhibitors and the HRs for benefit were similar in younger and older patients. Similarly to previous generation TKIs, despite the high response rate,disease progression eventually occurs and current clinical research is focused on novel strategies to delay the emergence of osimertinib resistance.Although preclinical and clinical researches have explored the interaction of first-generation EGFR-TKIs and cytotoxic agents [ $34,35,36,29,31,32,33]$, to date there are no data on clinical combination of chemotherapy with third-generation EGFR-TKIs, suc as osimertinib. In this study, we explored the efficacy of osimertinib combined with pemetrexed add platinumar in lung adenocarcinoma.A strong antitumor effect was observed when osimertinib was combined with pemetrexed add platinumar intercalated,By contrast osimertinib monotherapy.We strongly indicating that the addition of chemotherapy may potentiate the efficacy of osimertinib either in term of inhibition of tumor growth or appearance of relapses.Figure2C.1.Third generation Chemical-TKItherapy group PFS vs Third generation TKI monotherapy PFS. $P=0.005$. Mean Survival Time 40.73,95\%CI[33.56,47.90] VS 26.66 $95 \% \mathrm{CI}[22.89,30.44]$.Figure2D.1.Third generation Chemical-TKItherapy group OS vs Third generationTKI monotherapy OS. $\mathrm{P}=0.04$. Mean Survival Time $54.00,95 \% \mathrm{CI}[45.81,62.18]$ VS 39.72 $95 \% \mathrm{Cl}[29.18,50.27]$.Table 4.Third generation Chemical-TKItherapy group vs Third generation TKI therapy alone had a stronger effect on ORR and DCR.In a mouse model of PC9T790M xenograft tested in vitro,A strong anti-tumor effect was observed when osimertinib was combined with pemetrexed or cisplatin intercalated with osimertinib alone, no tumor became resistant, differently from the treatment with osimertinib alone which induced acquired resistance in $50 \%$ of mice. The combination treatment enhanced the percentage of fibrotic tissue within the xenograft tumors and the small tumors did not regrow when the administration of drugs was stopped, indicating a stronger efficacy in eradicating parenchymal tumor cells [39]. In PC9 and PC9T790M cell lines, analysis of signaling transduction pathways and protein related to cell death revealed that the combination treatment did not affect the 
intracellular transduction pathways,which were already completely suppressed by osimertinib alone,but strongly enhanced apoptosis signaling via caspase-7 activation. This observation may be of relevance for the results obtained in vivo.therefore, the selective pressure exerted by TKIs may promote the clonal expansion of resistant clones through different molecular mechanismsresults[37,38]. Our also provide a strong rationale for randomized studies comparing osimertinib monotherapy vs osimertinib plus chemotherapy, either in EGFR T790M positive and negative in EGFR-TKI naïve NSCLC patients. A phase III trial evaluating osimertinib combined with platinum-pemetrexed vs osimertinib monotherapy could be the right step forward to significantly prolong the survival of EGFR-mutated NSCLC patients[40].Combination cisplatin/carboplatin plus pemetrexed is the standard treatment regimen for advanced nonsquamous NSCLC and has been frequently used as the backbone of combination treatment[41,42,43].After eradicating tumors with heterogeneity, adding chemotherapy to osimertinib might increase the response rate and improve PFS and OS with a low incidence of grade $\geq 3$ AEs [44],Table5.For each of these AEs,the majority of Osimertinib with carboplatin-pemetrexed chemotherapy were grade 2 or 3 in severity $₫$ mild toxicities including skin

rash(58.32\%), anorexia(42.43\%),nausea(31.12\%),diarrhea(41.12\%),cough(36,23\%), anemia(32.12\%),

thrombocytopenia (32.12\%)events.Less than the common adverse effects of first generation ChemicalTKItherapy group.Our Cox multivariate analysis also showed that age $\geq 70$ years (in contrary to 55-69 years), mutation of genes positive compared to negative),Females compared to males,TKItherapy with chemicaltherapy compared to TKItherapy alone and chemicaltherapy alone all were significant prognostic factors.seeTable3.A large phase-3 trial with erlotinib including 586 younger and 163 elderly patients demonstrated a similar survival and quality of life (QoL) in both age groups, although a somewhat higher toxicity in the elderly was observed [45]. Clinical studies examining the elderly population are limited and often firm conclusions cannot be drawn $[46,47]$.In accordance with previous findings, females treated with erlotinib lived longer than males $[48,49]$.OS was significantly better in females than males $(p=0.04)$. Gene mutation improved survival time in patients. Lung adenocarcinoma with EGFR mutations was found to be $41.44 \%$ in this study.Recurring mutations have been reported in genes coding for epidermal growth factor receptors (EGFR) in $10-40 \%$ of adenocarcinomas [50,51,52], The mutant patients had a longer overall survival (OS) than the wild-type patients[54],Our patient with positive EGFR gene mutations demonstrated a longer progress-free OS survival than those with negative and wild-type gene.

Nevertheless,EGFR mutations were more frequent in patients over 75 than in younger patients: $17 \%$ versus 8.1\% $(P<0.0001)[55]$. The prognostic factors found in this study also included First add third TKltherapy with chemicaltherapy group had a longer OS survival time than the monotherapy TKI therapy or chemical therapy alone.For lung adenocarcinoma,chemical-TKI therapy was identified to be a good treatment option.Most limitations of our study relate to the nature of a non-interventional trial,The number of patients hampered the comparison of third generation Chemical-TKltherapy group effectiveness in a larger group of patients with or without EGFR mutations. The high rate of treatment discontinuations due to the severely ill patient population might have had an influence on data analysis and interpretation. 
Furthermore,The results of post-hoc analyses have to be interpreted with caution. Nevertheless,Our observational study generated invaluable results for real-life treatment decisions.

\section{Conclusion}

First-Third generation EGFR inhibitor combined with cytotoxic chemotherapy represents a suitable palliative treatment option in further therapy lines for elderly patients with advanced lung adenocarcinoma. The results obtained under real-life conditions add to our understanding of the benefits and risks of First-Third generation EGFR inhibitor combined with cytotoxic chemotherapy in routine clinical practice.

\section{Declarations}

\section{Ethical statement}

All patients signed informed consent before treatment, including their consent to treatment and clinical information for further prognostic factors analysis. This study was approved by the Research Ethics Committee of Shan-Xi Bethune Hospital,Taiyuan City,Shanxi Province,China

\section{Consent for publication}

We would like to submit the enclosed manuscript entitled "First-Third generation EGFR inhibitor combined with cytotoxic chemotherapy in elderly Patients with advanced lung adenocarcinom in routine clinical practice-results from A Subgroup Analysis. we wish to be considered for publication in this Journal, No conflict of interest exits in the submission of this manuscript, and manuscript is approved by all authors for publication. We would like to declare on behalf of our co-authors that the work described was original research that has not been published previously and not under consideration for publication elsewhere, in whole or in part. All the authors listed have approved the manuscript that is enclosed.

The Authors: Ming-Wei Chen, MD ${ }^{1}$,An-Tai He, MPH² ,Yi Pei, MD.

4.Availability of data and material『All data, models, and code generated or used during the study appear in the submitted article.

The raw/processed data required to reproduce these findings cannot be shared at this time as the data also forms part of an ongoing study.

5.Competing interests,Funding:This research received no grant from any funding agency in the public commercial or not-for profit sectors. The authors declare that there is no conflict of interest

\section{Authors' contributions:}


Chen, contributed to the conception of the study; He, performed the experiment;Chen, He,contributed significantly to analysis and manuscript preparation;He,performed the data analyses and wrote the manuscript;

Yi Pei, helped perform the analysis with constructive discussions.

\section{Acknowledgements}

Firstly, I would like to give my sincere gratitude to Prof.fu-bin Qiou my tutor who, with extraordinary patience and consistent encouragement, gave me great help by providing me with necessary materials, advice of great value and inspiration of new ideas. It is his suggestions that draw my attention to a number of deficiencies and make many things clearer. They graciously make considerable comments and sound suggestions to the outline of this paper. It is of great help for me to finish this thesis successfully.

The authors An-tai He

\section{Abbreviations}

NSCLC:

Non-small-cell lung cancer

\section{EGFR}

epidermal growth factor receptors

\section{$T K I s]$}

tyrosine kinase inhibitors

$\mathrm{AE}:$

Adverse event

Cl:

Confidence interval

DCR:

Disease control rate

ORR:

Objective response rate 
complete response

$P R$;

partial response ,

$S D$

stable disease

$P D$

progression disease

HR:

Hazard ratio

OS:

Overall survival

PFS:

Progression-free survival

QoL:

Quality of life

\section{References}

1.Torre LA,Bray F,Siegel RL,Ferlay J,Lortet-Tieulent J,Jemal A.Global cancer statistics, 2012. CA Cancer J Clin. 2015;65(2):87-108.

2.Travis WD. Pathology of lung cancer. Clin Chest Med. 2011;32(4):669-92.

3.Chang JS, Chen LT, Shan YS, Lin SF, Hsiao SY, Tsai CR, Yu SJ, Tsai HJ. Comprehensive analysis of the incidence and survival patterns of lung Cancer by Histologies, including rare subtypes, in the era of molecular medicine and targeted therapy: a nation-wide Cancer registry-based study from Taiwan. Medicine (Baltimore). 2015;94(24):e969.

4.Marchetti A, Martella C, Felicioni L, Barassi F, Salvatore S, Chella A, Camplese PP, Larussi T, Mucilli F, Mezzetti A, et al. EGFR mutations in non-small-cell lung cancer: analysis of a large series of cases and development of a rapid and sensitive method for diagnostic screening with potential implications on pharmacologic treatment. J Clin Oncol. 2005;23(4):857-65. 
5.Sugio K, Uramoto H, Ono K, Oyama T, Hanagiri T, Sugaya M, Ichiki Y, So T, Nakata S, Morita M, et al. Mutations within the tyrosine kinase domain of EGFR gene specifically occur in lung adenocarcinoma patients with a low exposure of tobacco smoking. Br J Cancer. 2006;94(6):896-903.

6.Varghese AM, Sima CS, Chaft JE, Johnson ML, Riely GJ, Ladanyi M, Kris MG. Lungs don't forget: comparison of the KRAS and EGFR mutation profile and survival of collegiate smokers and never smokers with advanced lung cancers. J Thorac Oncol. 2013;8(1):123-5.

7.Yarden Y, Sliwkowski MX. Untangling the ErbB signalling network. Nat Rev Mol Cell Biol. 2001;2(2):12737.

8.Novello S, Barlesi F, Califano R, Cufer T, Ekman S, Levra MG, Kerr K, Popat S, Reck M, Senan S, et al. Metastatic non-small-cell lung cancer: ESMO clinical practice guidelines for diagnosis, treatment and follow-up. Ann Oncol. 2016;27(suppl 5):v1-v27.

9.Brueckl WM. Treatment choice in EGFR-mutant non-small-cell lung cancer. Lancet Oncol. 2017;

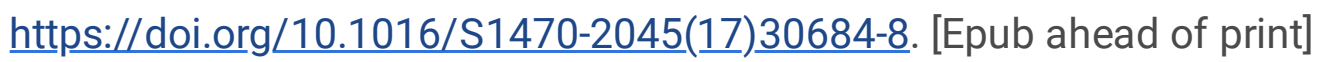

10.Mok TS, Wu YL, Ahn MJ, Garassino MC, Kim HR, Ramalingam SS, Shepherd FA, He Y, Akamatsu H, Theelen WS, et al. Osimertinib or platinum-Pemetrexed in EGFR T790M-positive lung Cancer. N Engl J Med. 2017;376:629-40.

11.Janne PA, Yang JC, Kim DW, Planchard D, Ohe Y, Ramalingam SS, Ahn MJ, Kim SW, Su WC, Horn L, et al. AZD9291 in EGFR inhibitor-resistant non-small-cell lung cancer. N Engl J Med. 2015;372:1689-99.

12.Soria JC, Ohe Y, Vansteenkiste J, Reungwetwattana T, Chewaskulyong B, Lee KH, Dechaphunkul A, Imamura F, Nogami N, Kurata T, et al. Osimertinib in untreated EGFR-mutated advanced non-small-cell lung Cancer. N Engl J Med. 2018;378:113-25.

13.Minari R, Bordi P, Del Re M, Facchinetti F, Mazzoni F, Barbieri F, Camerini A, Comin CE, Gnetti L, Azzoni $C$, et al. Primary resistance to osimertinib due to SCLC transformation: issue of T790M determination on liquid re-biopsy. Lung Cancer. 2018;115:21-7.

14.Ramalingam SS, Yang JC, Lee CK, Kurata T, Kim DW, John T, Nogami N, Ohe Y, Mann H, Rukazenkov Y, et al. Osimertinib as first-line treatment of EGFR mutation-positive advanced non-small-cell lung Cancer. $J$ Clin Oncol. 2018;36:841-9.

15.Yang Z, Yang N, Ou Q, Xiang Y, Jiang T, Wu X, Bao H, Tong X, Wang X, Shao YW, et al. Investigating novel resistance mechanisms to third-generation EGFR tyrosine kinase inhibitor Osimertinib in non-small cell lung Cancer patients. Clin Cancer Res. 2018;24:3097-107.

16.La Monica S, Madeddu D, Tiseo M, Vivo V, Galetti M, Cretella D, Bonelli M, Fumarola C, Cavazzoni A, Falco A, et al. Combination of Gefitinib and Pemetrexed prevents the acquisition of TKI resistance in NSCLC cell lines carrying EGFR-activating mutation. J Thorac Oncol. 2016;11:1051-63. 
17.Therasse P, Arbuck SG, Eisenhauer EA, Wanders J, Kaplan RS, Rubinstein L, Verweij J, Van Glabbeke M, Van Oosterom AT, Christian MC, Gwyther SG, European Organization for Research and Treatment of Cancer, National Cancer Institute of the United States, National Cancer Institute of Canada: New guidelines to evaluate the response to treatment in solid tumors. J Natl Cancer Inst. 2000, 92: 205-216. 10.1093/jnci/92.3.205.

18.Chmielecki J, Foo J, Oxnard GR, Hutchinson K, Ohashi K, Somwar R, Wang L, Amato KR, Arcila M, Sos $\mathrm{ML}$, et al. Optimization of dosing for EGFR-mutant non-small cell lung cancer with evolutionary cancer modeling. Sci Transl Med. 2011;3:90ra59.

19.Cavazzoni A, Alfieri RR, Carmi C, Zuliani V, Galetti M, Fumarola C, Frazzi R, Bonelli M, Bordi F, Lodola A, et al. Dual mechanisms of action of the 5-benzylidene-hydantoin UPR1024 on lung cancer cell lines. Mol Cancer Ther. 2008;7:361-70

20.Ramalingam SS, Yang JC, Lee CK, Kurata T, Kim DW, John T, Nogami N, Ohe Y, Mann H, Rukazenkov Y, et al. Osimertinib as first-line treatment of EGFR mutation-positive advanced non-small-cell lung Cancer. $J$ Clin Oncol. 2018;36:841-9.

21.La Monica S, Cretella D, Bonelli M, Fumarola C, Cavazzoni A, Digiacomo G, Flammini L, Barocelli E, Minari R, Naldi N, et al. Trastuzumab emtansine delays and overcomes resistance to the third-generation EGFR-TKI osimertinib in NSCLC EGFR mutated cell lines. J Exp Clin Cancer Res. 2017;36:174.

22. Takezawa K, Okamoto I, Okamoto W, Takeda M, Sakai K, Tsukioka S, Kuwata K, Yamaguchi H, Nishio $\mathrm{K}$, Nakagawa $\mathrm{K}$. Thymidylate synthase as a determinant of pemetrexed sensitivity in non-small cell lung cancer. Br J Cancer. 2011;104:1594-601.

1. Li T, Ling YH, Goldman ID, Perez-Soler R. Schedule-dependent cytotoxic synergism of pemetrexed and erlotinib in human non-small cell lung cancer cells. Clin Cancer Res. 2007;13:3413-22.

24.Han B, Jin B, Chu T, Niu Y, Dong Y, Xu J, Gu A, Zhong H, Wang H, Zhang X, et al. Combination of chemotherapy and gefitinib as first-line treatment for patients with advanced lung adenocarcinoma and sensitive EGFR mutations: a randomized controlled trial. Int J Cancer. 2017;141:1249-56.

25.Yang JC, Cheng Y, Murakami H, Yang P, He J, Nakagawa K, Kang JH, Kim J, Wnag X, Enatsu S, et al: Gefitinib with or without Pemetrexed in nonsquamous (NS) non-small cell lung Cancer (NSCLC) with EGFR mutation (Mut): final overall survival results from a randomized phase II trial. Ann Oncol 2018, 29:viii493-viii547. 4https://doi.org/10.1093/annonc/mdy1292.

26. Oizumi S, Sugawara S, Minato K, Harada T, Inoue A, Fujita Y, Maemondo M, Watanabe S, Ito K, Gemma A, et al. Updated survival outcomes of NEJ005/TCOG0902, a randomized phase II study of concurrent (C) versus sequential alternating $(S)$ gefitinib and chemotherapy in previously untreated non-small cell lung cancer (NSCLC) with sensitive epidermal growth factor receptor (EGFR) mutations. J Clin Oncol. 2017;35. 
27.Cui J, Zhang Y, Su D, Li T, Li Y. Efficacy of combined icotinib and pemetrexed in EGFR mutant lung adenocarcinoma cell line xenografts. Thorac Cancer. 2018;9:1156-65.

28.Feng X, Zhang Y, Li T, Li Y. Sequentially administrated of pemetrexed with icotinib/erlotinib in lung adenocarcinoma cell lines in vitro. Oncotarget. 2017;8:114292-9.

36.Giovannetti E, Lemos C, Tekle C, Smid K, Nannizzi S, Rodriguez JA, Ricciardi S, Danesi R, Giaccone G, Peters GJ. Molecular mechanisms underlying the synergistic interaction of erlotinib, an epidermal growth factor receptor tyrosine kinase inhibitor, with the multitargeted antifolate pemetrexed in non-small-cell lung cancer cells. Mol Pharmacol. 2008;73:1290-300.

29.Yu HA, Suzawa K, Jordan E, Zehir A, Ni A, Kim R, Kris MG, Hellmann MD, Li BT, Somwar R, et al. Concurrent alterations in EGFR-mutant lung cancers associated with resistance to EGFR kinase inhibitors and characterization of mTOR as a mediator of resistance. Clin Cancer Res. 2018;24:3108-18.

30.Blakely CM, Watkins TBK, Wu W, Gini B, Chabon JJ, McCoach CE, McGranahan N, Wilson GA, Birkbak $\mathrm{NJ}$, Olivas VR, et al. Evolution and clinical impact of co-occurring genetic alterations in advanced-stage EGFR-mutant lung cancers. Nat Genet. 2017;49:1693-704.

31.Silvia La Monica, Roberta Minari, Daniele Cretella, Lisa Flammini,_Claudia Fumarola, Mara Bonelli, Andrea Cavazzoni, Graziana Digiacomo, Maricla Galetti,Denise Madeddu,et al.Third generation EGFR inhibitor osimertinib combined with pemetrexed or cisplatin exerts long-lasting anti-tumor effect in EGFRmutated pre-clinical models of NSCLC.J ournal of Experimental \& Clinical Cancer Research. 2019;38: 222

32.La Monica, S., Minari, R., Cretella, D. et al. Third generation EGFR inhibitor osimertinib combined with pemetrexed or cisplatin exerts long-lasting anti-tumor effect in EGFR-mutated pre-clinical models of NSCLC. J Exp Clin Cancer Res 38, 222 (2019).

33.L.Gandhi,D.Rodríguez-Abreu,S.Gadgeel,et al.Pembrolizumab plus chemotherapy in metastatic nonsmall-cell lung cancer N Engl J Med, 378 (2018), pp. 2078-2092

34.J.C.Soria,Y.L.Wu,K.Nakagawa, et al.Gefitinib plus chemotherapy versus placebo plus chemotherapy in EGFR-mutation-positive non-small-cell lung cancer after progression on first-line gefitinib (IMPRESS): a phase 3 randomised trial Lancet Oncol,16(2015),pp.990-996

35.Y.Hosomi,S.Morita,S.Sugawara, etal.Gefitinib alone versus gefitinib plus chemotherapy for non-smallcell lung cancer with mutated epidermal growth factor receptor: NEJ009 study J Clin Oncol, 38 (2020), pp. 115-123

36.M.Takeda,I.Okamoto,K.Nakagawa. Survival outcome assessed according to tumor response and shrinkage pattern in patients with EGFR mutation-positive non-small-cell lung cancer treated with gefitinib or erlotinib J Thorac Oncol, 9 (2014), pp. 200-204 
37. Wheatley-Price P, Ding K, Seymour L, Clark GM, Shepherd FA. Erlotinib for advanced non-small-cell lung cancer in the elderly: an analysis of the National Cancer Institute of Canada clinical trials group study BR.21. J Clin Oncol. 2008;26(14):2350-7.

38.Lewis JH, Kilgore ML, Goldman DP, Trimble EL, Kaplan R, Montello MJ, Housman MG, Escarce JJ. Participation of patients 65 years of age or older in cancer clinical trials. J Clin Oncol. 2003;21(7):1383-9.

39.Vora N, Reckamp KL. Non-small cell lung cancer in the elderly: defining treatment options. Semin Oncol. 2008;35(6):590-6.

40.Cioffi P, Marotta V, Fanizza C, Giglioni A, Natoli C, Petrelli F, Grappasonni I. Effectiveness and response predictive factors of erlotinib in a non-small cell lung cancer unselected European population previously treated: a retrospective, observational, multicentric study. J Oncol Pharm Pract. 2013;19(3):246-53.

41.Van Meerbeeck J, Galdermans D, Bustin F, De Vos L, Lechat I, Abraham I. Survival outcomes in patients with advanced non-small cell lung cancer treated with erlotinib: expanded access programme data from Belgium (the TRUST study). Eur J Cancer Care (Engl). 2014;23(3):370-9.

42. Marchetti A, Martella C, Felicioni L, Barassi F, Salvatore S, Chella A, Camplese PP, Larussi T, Mucilli F, Mezzetti A, et al. EGFR mutations in non-small-cell lung cancer: analysis of a large series of cases and development of a rapid and sensitive method for diagnostic screening with potential implications on pharmacologic treatment. J Clin Oncol. 2005;23(4):857-65.

43.Sugio K, Uramoto H, Ono K, Oyama T, Hanagiri T, Sugaya M, Ichiki Y, So T, Nakata S, Morita M, et al. Mutations within the tyrosine kinase domain of EGFR gene specifically occur in lung adenocarcinoma patients with a low exposure of tobacco smoking. Br J Cancer. 2006;94(6):896-903.

44.Varghese AM, Sima CS, Chaft JE, Johnson ML, Riely GJ, Ladanyi M, Kris MG. Lungs don't forget: comparison of the KRAS and EGFR mutation profile and survival of collegiate smokers and never smokers with advanced lung cancers. J Thorac Oncol. 2013;8(1):123-5.

45. Lee DH, Lee JS, Kim SW, Rodrigues-Pereira J, Han B, Song XQ, et al. Three-arm randomised controlled phase 2 study comparing pemetrexed and erlotinib to either pemetrexed or erlotinib alone as second-line treatment for never-smokers with non-squamous non-small cell lung cancer. Eur J Cancer. 2013;49:311121.

46.Forest F,Patoir A,Dal-Col P,DaCruz V,Camy F,Stachowicz M,et al.Lepidic,Papillary Components and EGFR Mutations are Frequent in Patients With Lung Adenocarcinoma Who are Over 75 Years Old. Applied Immunohistochemistry \& Molecular Morphology.2019;27: 667-671

\section{Figures}




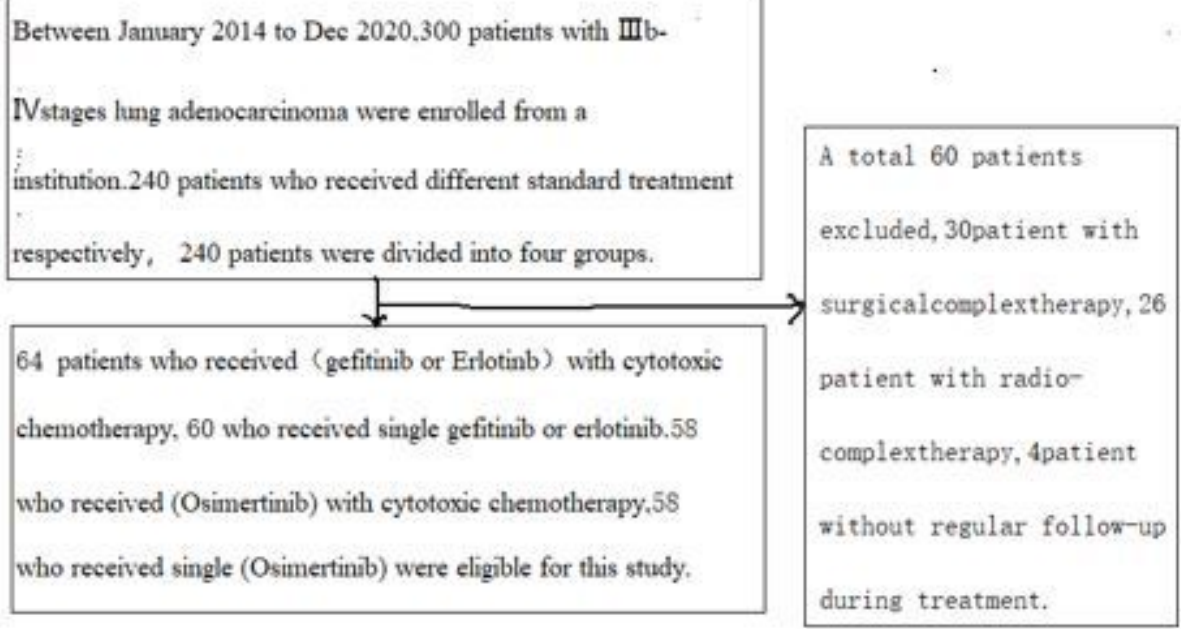

\section{Figure 1}

The flowchart of our study is shown in Fig. 1. 


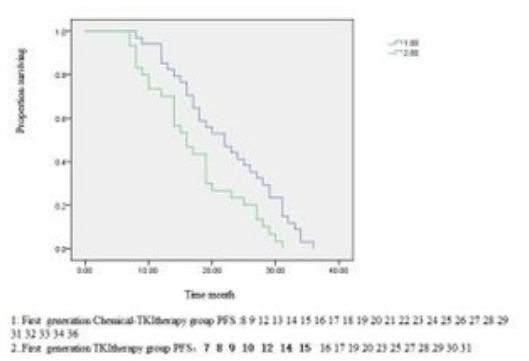

A

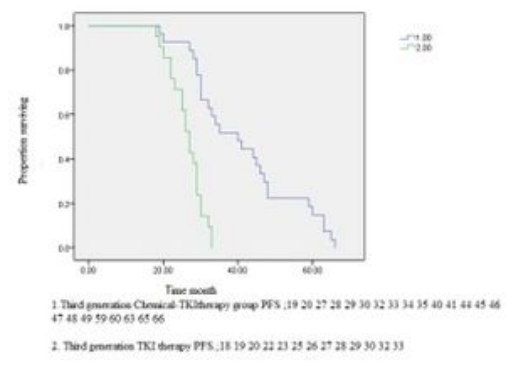

$\mathrm{C}$

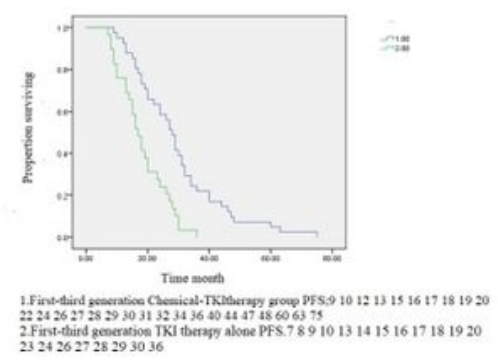

E

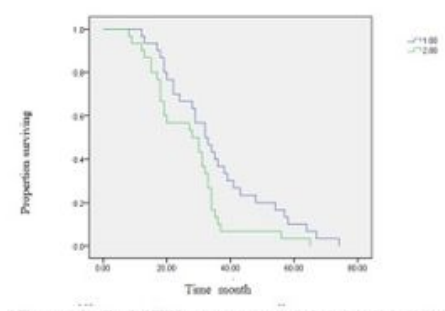

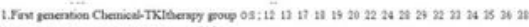

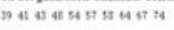

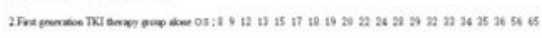

B

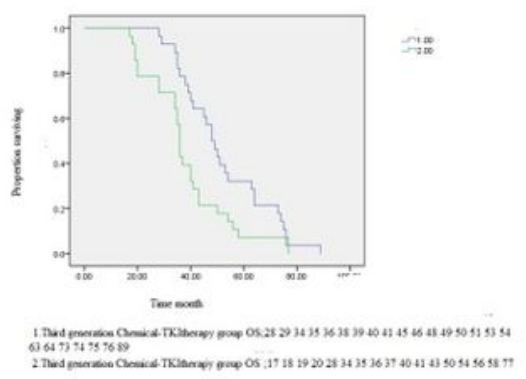

D

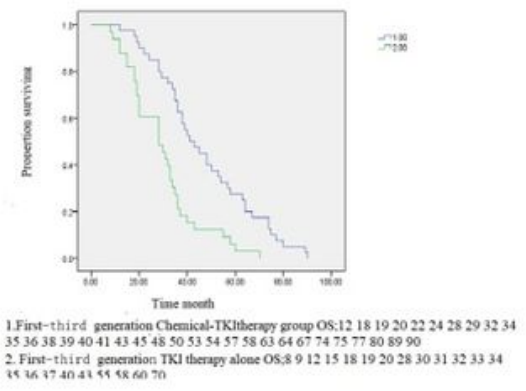

$\mathbf{F}$

\section{Figure 2}

A.First generation Chemical-TKItherapy group PFS vs First generation TKI therapy alone PFS. $P<0.05$. Mean Survival Time 22.00 month,95\%CI[16.29,27.70] VS 16.00 month 95\%CI[11.98,20.01].Figure2 B.1.First generation Chemical-TKItherapy group OS vs First generation TKI therapy alone OS. P<0.05. Mean Survival Time 32.00 month,95\% CI[25.29,3871] VS 28.00 month, 95\%Cl[14.58,41.41]. Figure2C.1.Third generation Chemical-TKItherapy group PFS vs Third generation TKI therapy PFS. 
$\mathrm{P}<0.001$. Mean Survival Time 40.00,95\%CI[28.12,51.87] VS 26.66 95\%CI[24.77,29.22].Figure2D.1.Third generation Chemical-TKItherapy group OS vs Third generation TKI therapy OS.P<0.05. Mean Survival Time 48.00.95\% CI[42.81,53.18] VS 36.00. 95\% CI[34.71,38.28]. Figure2E1.First-Third generation ChemicalTKItherapy group PFS vs.First-Third generation TKI therapy alone PFS. $P<0.001$. Mean Survival Time $28.00,95 \% \mathrm{Cl}[24.86,31.11]$ VS $17.0095 \% \mathrm{Cl}[13.83,20.16]$.Figure2F.1.First-Third generation ChemicalTKItherapy group OS vs First-Third generation TKI therapy alone OS.P $<0.001$. Mean Survival Time $41.00 .95 \% \mathrm{CI}[31.70,50.30]$ VS 29.00. 95\% CI[17.68,38.31]. 